\title{
Optimisation of the enzymatic synthesis of $n$-octyl oleate with immobilised lipase in the absence of solvents
}

\author{
JMS Rocha,* MH Gil and FAP Garcia \\ Department of Chemical Engineering, University of Coimbra, Polo II-Pinhal de Marrocos 3030 Coimbra, Portugal
}

\begin{abstract}
The enzymatic synthesis of $\boldsymbol{n}$-octyl oleate by direct esterification of the oleic acid and the octanol in a solvent-free medium was previously shown to be efficiently catalysed by a lipase from Rhizomucor miehei covalently linked to a graft copolymer, the partially hydrolysed poly(ethylene)-g co-hydroxyethyl methacrylate (PE-g co-HEMA). In this work we went further towards an optimisation of the production of $\boldsymbol{n}$-octyl oleate taking into account several parameters that affect the catalytic activity of the preparation. The physical characteristics of the support, such as the particle size and the degree of hydrolysis of the copolymer, the amount of lipase used in the method of immobilisation, the water content of the reaction mixture and the operational conditions of reaction, in particular the temperature, were evaluated in order to achieve not only high activities but also a good stability of the preparation.
\end{abstract}

(C) 1999 Society of Chemical Industry

Keywords: lipase; immobilisation; biocatalysis; ester synthesis

\section{INTRODUCTION}

Esters are one of the most important classes of organic compounds and because of their wide variation in composition and properties, they find widespread uses as solvents, plasticisers, perfumes, flavours and in medicine. Some polymerised esters can also be used as resins, plastics and textile fibres. ${ }^{1}$ Recently lipasecatalysed reactions have increasingly received greater consideration relative to the traditional chemical synthetic methods particularly in the production of natural flavours and fragrances. ${ }^{2-5}$ This is due to the regio- and stereospecificity expressed by most lipases, the mild operation conditions, the degree of purity of the obtained products and their acceptability in the food industry. Also, there is a large potential of applications opened by various interesterification reactions, including the synthesis of new compounds such as monomeric intermediates ${ }^{6}$ or non-natural substrates. ${ }^{5}$ Enzymatic syntheses of esters have been reported from short-chain flavour esters, ${ }^{7}$ with application in the cosmetic and food additives industries (including methyl and ethyl esters that are useful reactants in lipase-catalysed interesterifications for production of tailored triglycerides ${ }^{8}$ or as diesel fuel additives and substitutes ${ }^{9}$ ), to long-chain esters, like wax esters, with applications as lubricants or plasticisers. ${ }^{10}$
Rhizomucor miehei lipase is one of the most widely used lipases to catalyse esterification and interesterification reactions. The free Rhizomucor miehei lipase in a powder form (specified as Esterase 30000 from Gist Brocades, France) was used for the esterification of butanol with butyric acid. ${ }^{11}$ However, the lipase from Rhizomucor miehei is most often used in an immobilised form, a macroporous anion exchange resin (Lipozyme ${ }^{\mathbb{R}}$ ), commercially available from Novo Nordisk. Literature reports concerning the immobilisation of the lipase (EC 3.1.1.3) from Rhizomucor miehei (available as a crude extract from Novo Nordisk) on other supports are very scarce. ${ }^{7,12-14}$ Rhizomucor miehei lipase has been used for direct esterification reactions with ${ }^{7,8}$ and without ${ }^{10,14}$ additional solvents, for the synthesis of esters by transesterification, ${ }^{3,15}$ for the alcoholysis of triglycerides, ${ }^{9,16}$ for the acidolysis of triglycerides $^{13,17,18}$ and for triglyceride synthesis. ${ }^{19,20}$

Each ester or triglyceride synthesis is a specific problem. The most suitable lipase preparation as well as the best experimental conditions to achieve high conversion yields must be carefully investigated. Therefore, the design of tailored supports, with controlled hydrophylicity, for the immobilisation of lipases is an objective. In this work we report the use of the graft copolymer poly(ethylene)- $g$ co-hydroxyethyl

\footnotetext{
* Correspondence to: JMS Rocha, Department of Chemical Engineering, University of Coimbra, Polo II-Pinhal de Marrocos 3030 Coimbra, Portugal

E-mail: jrocha@eq.uc.pt

Contract/grant sponsor: Junta Nacional de Investigação Científica, Lisbon; contract/grant number: PRAXIS 2/2.1/BIO/34/94

(Received 19 March 1998; revised version received 25 January 1999; accepted 11 February 1999)
} 
methacrylate, already presented in previous works, ${ }^{12,14}$ where the efficiency and usefulness of this material were made evident.

The reactors for enzymatic esterifications must be efficient, ie the operating volume must be small and the degree of conversion of substrates to products must be high. One possibility for increasing the efficiency is to carry out the reaction with no addition of solvents, whenever possible. This makes the reactor volume smaller, the substrate concentrations higher and avoids additional solvent recovery operations. Nevertheless, different strategies have to be used in the synthesis of short-chain and long-chain esters. The development of immobilised lipase preparations for lipase-catalysed synthesis reactions is required in order to create a more convenient environment for the expression of lipolytic activity towards the desired products.

This work was aimed to optimise the conditions for the $n$-octyl oleate synthesis with lipase from Rhizomucor miehei immobilised onto PE- $g$ co-HEMA in the absence of additional solvents.

\section{MATERIALS AND METHODS}

\subsection{Materials}

Oleic acid and $n$-octanol (analytical grade) were from Merck, Germany. Low density $\left(\rho=0.920 \mathrm{~g} \mathrm{~cm}^{-3}\right)$ poly(ethylene) was kindly donated by Neste Chemicals, Sines, Portugal. The poly(ethylene), in a granular form, was crushed in a hammer mill and sieved. The 2-hydroxyethyl methacrylate (HEMA) was obtained from Aldrich-Chemie, Germany. Lipase from Rhizomucor miehei, Lipozyme ${ }^{\circledR} 10000 \mathrm{~L}$, was a gift from Novo Nordisk, Denmark.

\subsection{Copolymer preparation and characterisation}

A suspension of the poly(ethylene) powder in a methanolic solution of HEMA $(10 \% \mathrm{v} / \mathrm{v})$ was irradiated in a $\mathrm{Co}(60)$ source at $18.3 \mathrm{rad} \mathrm{s}^{-1}$ for $18 \mathrm{~h}$, at room temperature, in the presence of air. The suspension was filtered and thoroughly washed with methanol. The homopolymer was removed by Soxhlet extraction with methanol and the solid was dried to constant mass, at $40^{\circ} \mathrm{C}$ in a vacuum oven. The yield of grafting of the resulting copolymer was determined by the percentage increase in mass from the starting polymer. The PE- $g$ co-HEMA was partially hydrolysed by boiling with $1 \mathrm{moldm}^{-3} \mathrm{NaOH}$ for $4 \mathrm{~h}$ under total reflux conditions. The degree of hydrolysis was determined by evaluating the $-\mathrm{COOH}$ groups present in the copolymer (titration method). The specific surface area of the copolymer particles was determined by the gas adsorption method, using the ASAP 2000 (Accelerated Surface Area and Porosimetry), from Micromeritics. Because of the low specific surface area of PE- $g$ co-HEMA particles, krypton (more suitable for specific areas below $10 \mathrm{~m}^{2} \mathrm{~g}^{-1}$ ) was used instead of nitrogen, currently used with porous materials. As a matter of fact the saturation pressure of krypton is $p_{0}=2.7-3.2 \mathrm{~mm} \mathrm{Hg}$ while for nitrogen it is $p_{0}=780$ $830 \mathrm{~mm} \mathrm{Hg}$.

\subsection{Lipase immobilisation procedure}

Lipase was covalently immobilised onto PE- $g$ coHEMA in a three-step procedure, as previously described. ${ }^{14}$ In the first step the carboxylic groups were activated with carbodiimide and spacer arms of 1,6-diaminohexane were inserted in the PE-g coHEMA. The second step was the activation of the $-\mathrm{NH}_{2}$ groups with glutaraldehyde, and the third step was the reaction of immobilisation of the lipase.

\subsection{Esterification reaction}

The direct esterification of octanol $\left(5 \mathrm{~cm}^{3}\right)$ and oleic acid $\left(1.5 \mathrm{~cm}^{3}\right)$, with $10 \mathrm{~mm}^{3}$ of water typically added, was done in McCartny bottles, at $37^{\circ} \mathrm{C}$ with magnetic stirring. The reaction time was started when the lipolytic preparation was added to the reactants and the reaction was carried out for $24 \mathrm{~h}$. The ester content was quantified by calculating the residual fatty acid in the reaction mixture. Samples were diluted in ethanol and titrated with standardised $1 \mathrm{moldm}^{-3} \mathrm{KOH}$ solution in ethanol, using phenolphthalein as the end point indicator.

\subsection{Lipase activity}

Lipase activity (free or immobilised), was determined by hydrolysis of triolein. The hydrolytic reaction was chosen as it is more rapid than the ester synthesis reaction. An emulsion of $0.5 \mathrm{~g}$ triolein, $2.5 \mathrm{~g}$ Triton $\mathrm{X}-100,5 \mathrm{~cm}^{3}$ of Tris/ $\mathrm{HCl}$ buffer $\left(50 \mathrm{mmol} \mathrm{dm}^{-3}\right.$, $\mathrm{pH} 8.6$ ) and $2 \mathrm{~cm}^{3}$ of water was homogenised using a magnetic stirrer and stabilised at $50^{\circ} \mathrm{C}$ for $10 \mathrm{~min}$. The reaction was started by the addition of free or immobilised lipase, and after the reaction time $(1 \mathrm{~min}$ in the case of free lipase or $5 \mathrm{~min}$ in the case of immobilised lipase) the reaction mixture was diluted in ethanol and titrated with a standard $1 \mathrm{moldm}^{-3}$ $\mathrm{KOH}$ solution in ethanol. A blank was prepared in a similar way but without the addition of lipase. One unit of lipolytic activity (U) was defined as the amount of lipase that released $1 \mu \mathrm{mol}$ of free fatty acids per minute under the operating conditions.

In esterification reactions, one unit of synthesis activity (SU) was defined as the amount of lipase (free or immobilised) that catalysed the synthesis of $1 \mathrm{~mol}$ of $n$-octyl oleate per hour and per $\mathrm{dm}^{3}$ of reaction mixture (defined in Section 2.4). The crude lipase extract, under conditions of non inhibitory effect of water, showed a synthesis activity of $0.30 \mathrm{SU}$ per $\mathrm{cm}^{3}$ of crude extract.

\section{RESULTS AND DISCUSSION}

\subsection{Influence of support characteristics}

The influence of the average particles size of the support on the activity of the resulted preparation for the synthesis of $n$-octyl oleate is shown in Fig 1 and Table 1. These results indicate that for the same mass 


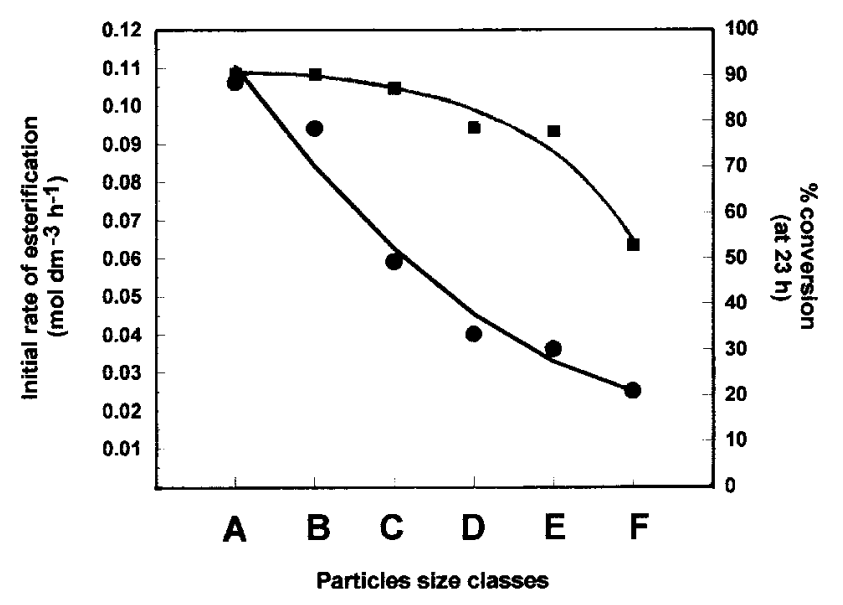

Figure 1. Effect of support particles average size on both initial rate of $n$ octyl oleate synthesis and conversion at $23 \mathrm{~h}$ of reaction time (PE-g coHEMA $69 \%$ grafting; $2 \mathrm{~h}$ hydrolysis; sieving separation of particles). initial rate; $\mathbf{\square}, \%$ conversion.

of copolymer and using the same immobilisation procedure smaller particles give higher catalytic activities. The small values of the specific surface area, as well as the low synthesis activity per unit surface area, shown in Table 1, suggest that the particles are non-porous and, therefore, the lipase is essentially bound to the external surface. The increase of the initial rate of ester synthesis when the biocatalyst particles sizes decreased can thus be explained by the increase in the specific surface area. If the reaction was allowed to proceed for a longer period (eg $23 \mathrm{~h}$ in Fig 1) the ester conversion increased as the particle size decreased, as expected, reaching a plateau for particles smaller than those of class C; this means that by the end of that period, the equilibrium (not affected by the catalyst) was reached when the particles were smaller but had higher specific activities.

The interpretation and comparison of information in the literature concerning the effect of operational factors on enzyme activity and stability can be incorrect if based only on initial reaction rates or the extend of conversion after a fixed reaction time but neglecting the support characteristics (see Fig 1, size classes $\mathrm{A}$ to $\mathrm{D}$ ). However, initial rates of reaction were used in this study to analyse the effects of particles size or the use of particles of one only size class. Of the particle sizes assessed (Table 1) class A $(150-250 \mu \mathrm{m})$ gave a preparation with the highest activity. These small particles have a tendency to float and to

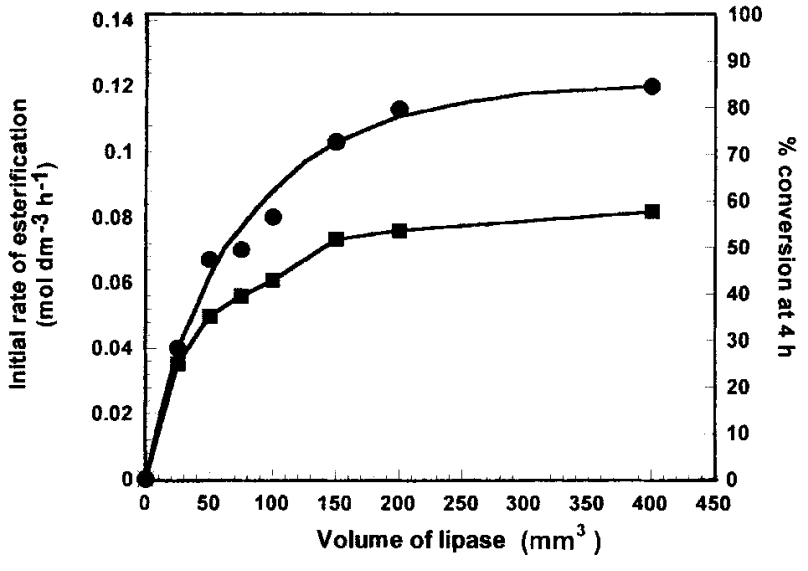

Figure 2. Influence of the volume of lipase crude extract (total protein content of $57 \mathrm{mg} \mathrm{cm}^{-3}$ ) added in the immobilisation process per $50 \mathrm{mg}$ of support on the initial rate of $n$-octyl oleate synthesis and on the conversion at $4 \mathrm{~h}$ of reaction time (PE- $g$ co-HEMA $100 \%$ grafting; $4 \mathrm{~h}$ hydrolysis; PE particles average size: $150-250 \mu \mathrm{m})$. $\bullet$, initial rate; $\mathbf{\square} \%$ conversion.

agglomerate, which is a disadvantage if they are used in reactors other than stirred tank reactors (BSTR or CSTR). Even in stirred tank reactors, there are losses of biocatalyst through sampling and between successive reutilisations.

In order to obtain carboxylic groups on the support surface required for the insertion of spacer arms, the poly(ethylene)- $g$ co-hydroxyethyl methacrylate (120\% graft) was hydrolysed. Earlier work ${ }^{12}$ showed that a hydrolysis time of $2-4 \mathrm{~h}$ was enough to obtain $c 50 \%$ hydrolysis. The evolution of the degree of hydrolysis was approximately linear with time in the first $2 \mathrm{~h}$, when the more accessible side chain groups are being hydrolysed and progressed thereafter at a decreasing rate.

\subsection{Influence of the amount of lipase}

More recently, Rocha et $a l^{14}$ established the best conditions for the immobilisation of the lipase via the insertion of spacer arms of 1,6-diaminohexane activated with glutaraldehyde. The amount of lipase used in the attachment solution in the last step of the immobilisation procedure was also reduced. The crude lipase contained $57 \mathrm{mg}$ protein $\mathrm{cm}^{-3}$, as determined by a modified Lowry method. ${ }^{21}$ As shown in Fig 2, the preparation gave high esterification activities when small amounts of lipase were used for immobilisation; a plateau was reached when $200 \mathrm{~mm}^{3}$ (11.4 mg protein content) of lipase (Lipozyme ${ }^{\mathbb{R}}$

Table 1. Specific surface area for different particle size classes and related synthesis activity of the biocatalyst

\begin{tabular}{|c|c|c|c|c|c|c|}
\hline Class & $A$ & $B$ & C & $D$ & $E$ & $F$ \\
\hline Particle size $(\mu \mathrm{m})$ & $150-250$ & $297-354$ & $420-500$ & $500-595$ & $595-707$ & $>707$ \\
\hline Surface area $\left(\mathrm{m}^{2} \mathrm{~g}^{-1}\right)$ & $0.471 \pm 0.034$ & $0.350 \pm 0.024$ & $0.247 \pm 0.016$ & $0.214 \pm 0.017$ & nd & nd \\
\hline Synthesis activity [SU] $\left(\mathrm{mol} \mathrm{dm}^{-3} \mathrm{~h}^{-1}\right)$ & 0.106 & 0.094 & 0.059 & 0.040 & 0.036 & 0.025 \\
\hline Specific synthesis activity ( $\mathrm{g}^{-1}$ support $)$ & 2.12 & 1.88 & 1.18 & 0.80 & 0.72 & 0.50 \\
\hline Specific synthesis activity ( $\mathrm{m}^{-2}$ surface area) & 4.5 & 5.4 & 4.8 & 3.7 & & \\
\hline
\end{tabular}

nd - not determined because of the reduced significance due to the heterogeneity of particles size and shape. 


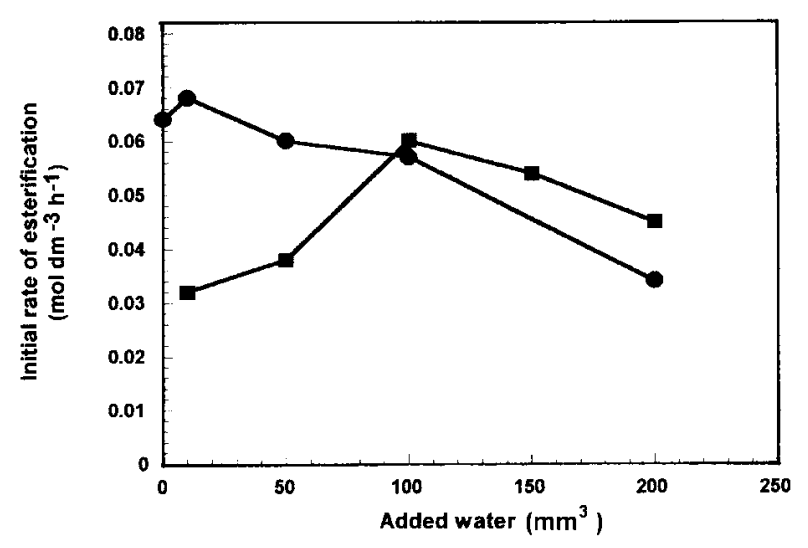

Figure 3. Effect of total content of water added to the reaction mixture on initial rate of $n$-octyl oleate synthesis, with the lipolytic preparation non-dried (๑) and vacuum-dried ( $\square$ ) (PE-g co-HEMA 91\% grafting; $4 \mathrm{~h}$ hydrolysis; PE particles average size: $150-250 \mu \mathrm{m})$.

$10000 \mathrm{~L})$ were added to a starting copolymer mass of $50 \mathrm{mg}$. With reference to previous work, ${ }^{14}$ it was confirmed that $200 \mathrm{~mm}^{3}$ was the amount of crude extract that should be added to $50 \mathrm{mg}$ of copolymer for the immobilisation of the lipase with maximal expressed activity. However, ester synthesis activities were improved, in this work, which could be due to differences in the characteristics of the supports used previously.

Considering the amount of crude extract used for immobilisation, a comparison of the esterification activity of immobilised and free lipase preparation in equivalent volumes of crude extract showed that the immobilised preparation was more than twice as active under the 'optimised conditions' defined later. This illustrated the support affinity for the lipase relative to other proteins.

\subsection{Influence of the water content}

Different amounts of water were added to the reaction mixture of alcohol and acid. A small amount of water is needed to hydrate and activate the immobilised lipase. However, in the case of esterification reactions the water may limit the initial rate and displace the equilibrium point. The total initial water content was calculated by considering both the water directly added to the reaction mixture and the water included in the lipolytic preparation. Two different supportlipase systems were used: in one, the particles were vacuum-dried at $40^{\circ} \mathrm{C}$ for $24 \mathrm{~h}$ to reach a hydration level of $7 \%(\mathrm{w} / \mathrm{w})$, while in the other the particles were not dried, and the water was just removed by filtration to have a final water content of about $200 \%$ (w/w). As shown in Fig 3 the amount of water added to the reaction mixture to give maximum enzyme activity was different for the dried and the non-dried preparations. For the non-dried preparation the highest activity was obtained when $10 \mathrm{~mm}^{3}$ of water (equivalent to $0.15 \%$ $(\mathrm{v} / \mathrm{v}))$ were added to the reaction mixture. However, $100 \mathrm{~mm}^{3}$ of water $(1.5 \%(\mathrm{v} / \mathrm{v}))$ were required to maximise the activity of the vacuum-dried particles. In both cases the overall content of water in the system was similar. The addition of $100 \mathrm{~mm}^{3}$ of water to the vacuum-dried preparation restored the catalytic activity to a value similar to the activity of the non-dried preparation, allowing one to conclude that the previous dehydration of the lipase preparation had no significant effect on the activity. The crucial role of water in the expression of the lipolytic activity was reinforced and these results showed good hydrophylic compatibility between the support and the reaction mixture for the establishment of a favourable microenvironment around the lipase.

\subsection{Influence of temperature on lipase stability}

The operational conditions of the esterification reaction must be established to achieve not only a high activity but also a good stability of the enzyme preparation. In the case of temperature, the esterification activity was found to have a maximum at $55^{\circ} \mathrm{C}$ for the same model reaction. ${ }^{14}$ However, the thermal stability of either the free or immobilised lipase at $50^{\circ} \mathrm{C}$ was not satisfactory, as observed in Fig 4 where hydrolytic activities evaluated after different incuba-
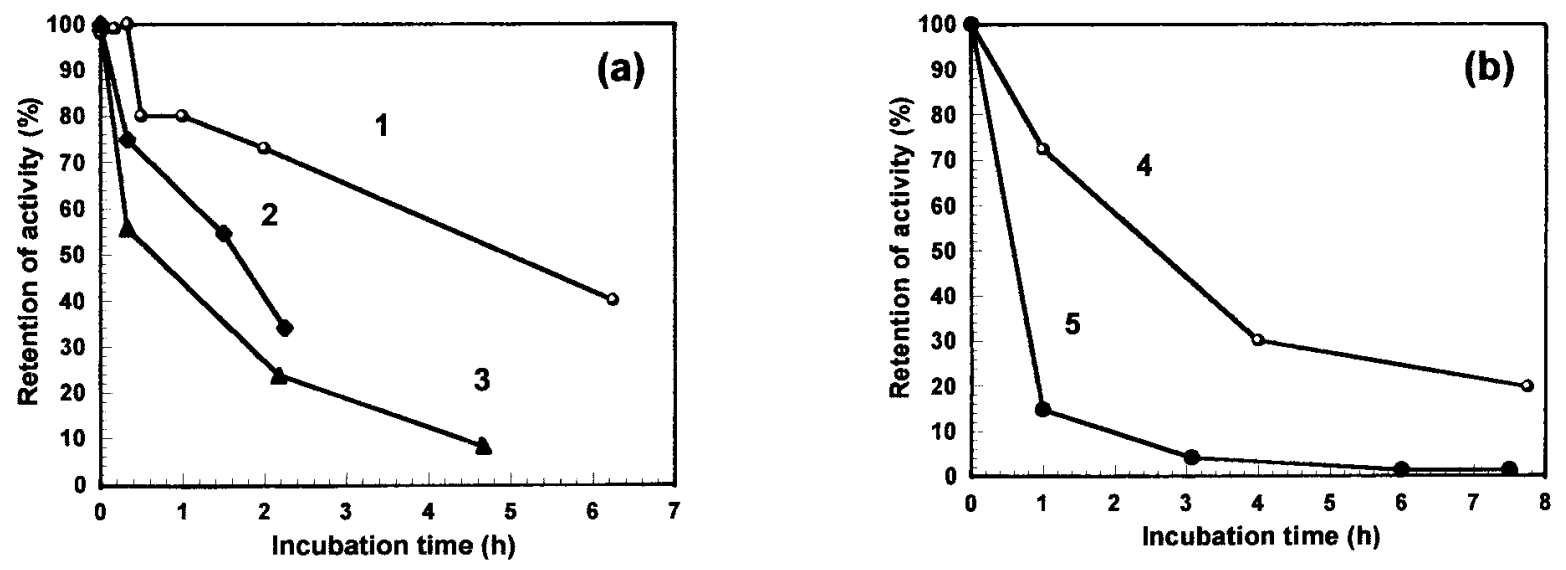

Figure 4. Thermal stability of lipase at $50^{\circ} \mathrm{C}$ in (a) aqueous phase and (b) $n$-hexane (1-free lipase, Lipozyme ${ }^{\circledR} 10000 \mathrm{~L}$, as liquid crude extract; 2 -immobilised lipase and phosphate buffer; 3 -immobilised lipase and Tris/HCl buffer; 4-vacuum-dried immobilised lipase and $n$-hexane; 5 -non-dried immobilised lipase and $n$-hexane). 
tion periods, in the absence of substrate, are shown. In Fig 4(a) the thermal stabilities of the free lipase (Lipozyme ${ }^{\circledR} 10000 \mathrm{~L}$ ) and the lipase immobilised onto PE- $g$ co-HEMA were studied in an aqueous environment. The immobilised lipase was incubated in a phosphate buffer $\left(100 \mathrm{mmoldm}^{-3}, \mathrm{pH}=7\right)$ and in a Tris/ $\mathrm{HCl}$ buffer $\left(50 \mathrm{mmol} \mathrm{dm}^{-3}, \mathrm{pH}=8.6\right)$. In all cases the thermal stability was low and the aqueous environment of the enzyme was considered to be responsible for the loss of activity. A similar study was made in an organic phase by incubating the lipase preparations (dried and non-dried) in $n$-hexane at the same temperature of $50^{\circ} \mathrm{C}$ and the results are shown in Fig 4(b). At the end of the incubation time in the organic solvent, both preparations were washed with distilled water and filtered under reduced pressure, and the hydrolytic activity was immediately determined at the same temperature of incubation $\left(50^{\circ} \mathrm{C}\right)$. The effect of water surrounding the enzyme on the loss of lipolytic activity at such a high temperature is evident in Fig 4(b) where a higher thermal stability can be observed in the case of the vacuum-dried preparation. However, in all cases the thermal stabilities at $50^{\circ} \mathrm{C}$ were poor, in both the aqueous and the organic phases, and were not improved when the lipase was immobilised in PE-g co-HEMA.

In strong contrast to this, better results were obtained for the thermal stability at a lower temperature $\left(37^{\circ} \mathrm{C}\right)$ in similar solutions. When the vacuumdried preparation was incubated at $37^{\circ} \mathrm{C}$, either in phosphate buffer or in $n$-hexane, in the absence of a substrate, the hydrolytic activity retention after $24 \mathrm{~h}$ of incubation was $75 \%$ and $125 \%$ (data not shown), respectively, as compared with the activities at the start of the incubation periods. Again, the effect of temperature was also influenced by the environment around the enzyme, the aqueous environment being more damaging to the enzymatic activity. This can be compared with the results obtained with a Candida rugosa lipase immobilised on a microporous polypropylene support ${ }^{22}$ incubated for different periods of time in distilled water at different temperatures: the residual activity assayed at $37^{\circ} \mathrm{C}$ with edible pork lard as substrate and incubating for $5 \mathrm{~h}$, sharply decreased at temperatures above $45^{\circ} \mathrm{C}$, retaining only about $20 \%$ of the initial activity that was expressed at $40^{\circ} \mathrm{C}$. The temperature of $37^{\circ} \mathrm{C}$ was chosen as the more convenient in further experiments, particularly when the preparation was to be reused.

Thermostability at high temperature is related to lipase source, to the nature of the solvent, to the type of reaction and the type of substrate, to the water content or water activity of the reaction system, as well as the use of the lipase in a free or immobilised form and the type of support. Accordingly, the half-lives that have been reported ${ }^{23}$ vary widely and in the case of Rhizomucor miehei range from a few to $1600 \mathrm{~h}$. The operational stability of the preparation was also studied using the same model reaction of $n$-octyl oleate synthesis at $37^{\circ} \mathrm{C}$. The half-life of the prepara- tion under strong mixing conditions in a magnetically stirred reactor, calculated from the decay in the initial rate of esterification in multiple reutilisations, was $c 150 \mathrm{~h}$ for the non-dried lipolytic preparation and $c 220 \mathrm{~h}$ for the vacuum-dried preparation. Very strong mixing conditions were used, first to test the mechanical strength of the support, and second to guarantee that diffusion limitations were minimised. Under the same hydrodynamic conditions, the commercially available preparation of the same lipase (Lipozyme ${ }^{\circledR}$, from Novo Nordisk) immobilised on an exchange ionic resin had a half-life three or four times lower. However, in both cases the activity decrease in successive reutilisations of the biocatalyst was strongly and negatively affected by particle erosion and consequent sampling losses. ${ }^{24}$

Lipozyme $^{\mathbb{R}}$ is preferably used in packed tubular reactors, which explains the high operational stability; ${ }^{25}$ however, the catalytic preparation presented here created good expectations for use in stirred reactors.

The optimised experimental conditions found for the initial rate of synthesis of $n$-octyl oleate were the following: the lipase content of $200 \mathrm{~mm}^{3}$ of Lipozyme $^{\circledR} 10000 \mathrm{~L}$ (11.4 mg of total protein) was immobilised onto $50 \mathrm{mg}$ of PE- $g$ co-HEMA (120\% degree of grafting and $4 \mathrm{~h}$ of hydrolysis) with an average particle size of $150-250 \mu \mathrm{m}$; this preparation was filtered at reduced pressure and dispersed in a reaction mixture of octanol $\left(5 \mathrm{~cm}^{3}\right)$ and oleic acid $\left(1.5 \mathrm{~cm}^{3}\right)$, at $37^{\circ} \mathrm{C}$, to which $10 \mathrm{~mm}^{3}$ of water were added. Under these conditions an initial rate of $0.145 \mathrm{moldm}^{-3} \mathrm{~h}^{-1}$ for the $n$-octyl oleate formation and a conversion of $82 \%$ after $10 \mathrm{~h}$ of reaction were obtained. The reaction profile can be seen in Fig 5 .

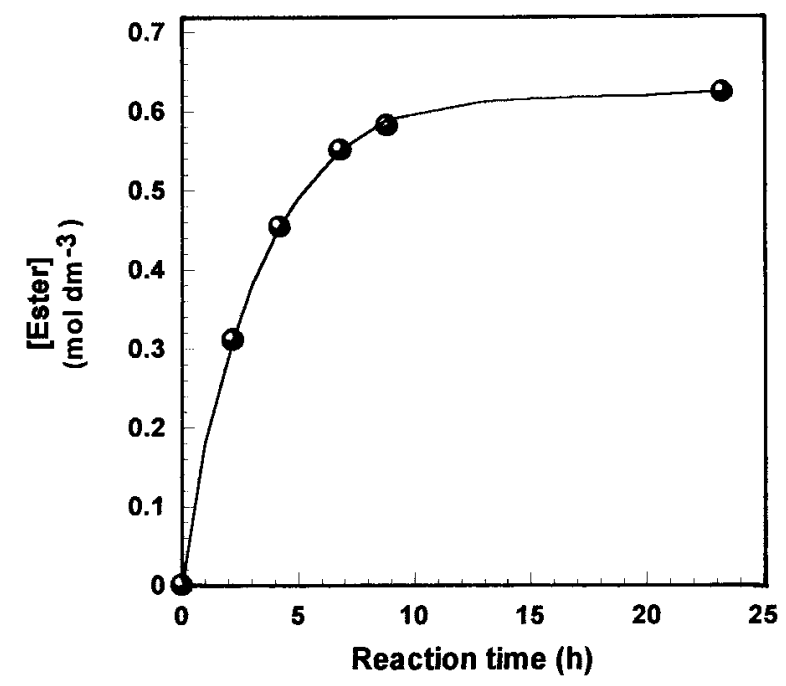

Figure 5. Profile of the enzymatic synthesis of $n$-octyl oleate under optimised conditions (PE-g co-HEMA $120 \%$ grafting; $4 \mathrm{~h}$ hydrolysis; PE particles average size: $150-250 \mu \mathrm{m} ; 200 \mathrm{~mm}^{3}$ of Lipozyme ${ }^{\mathbb{B}} 10000 \mathrm{~L}$ used in the immobilisation procedure; $10 \mathrm{~mm}^{3}$ of water added to the reaction mixture; hydrated lipolytic preparation; $T=37^{\circ} \mathrm{C}$ ). 


\section{ACKNOWLEDGEMENTS}

This project was financially supported by the Junta Nacional de Investigação Científica, of Lisbon (Project PRAXIS 2/2.1/BIO/34/94), which is gratefully acknowledged.

\section{REFERENCES}

1 Kirk and Othmer, Encyclopedia of Chemical Technology, vol 8 2nd edn, John Wiley \& Sons Inc, USA. p 366 (1967).

2 Welsh FW and Williams RE, Lipase-mediated production of ethyl butyrate and butyl butyrate in nonaqueous systems. Enzyme Microb Technol 12:743-748 (1990).

3 Chulalaksananukul W, Condoret JS and Combes D, Kinetics of geranyl acetate synthesis by lipase-catalysed transesterification in n-hexane. Enzyme Microb Technol 14:293-298 (1992).

4 Gatfield IL, Bioreactors for industrial production of flavours: use of enzymes, in Bioformation of Flavours, Ed by Patterson RLS, Charlwood BV, Macleod G and Williams AA, Royal Society of Chemistry, Cambridge. pp 171-185 (1992).

5 Wong $\mathrm{CH}$ and Whitesides GM, Enzymes in Synthetic Organic Chemistry, Tetrahedron organic chemistry series, vol 12, 1st edn, Elsevier Science, UK (1994).

6 Hajjar AB, Nicks PF and Knowles CJ, Preparation of monomeric acrylic ester intermediates using lipase catalysed transesterificarions in organic solvents. Biotechnol Lett 12(11):825-830 (1990).

7 Manjón A, Iborra JL and Arocas A, Short-chain flavour ester synthesis by immobilized lipase in organic media. Biotechnology Lett 13(5):339-344 (1991).

8 Bloomer S, Adlercreutz P and Mattiasson B, Facile synthesis of fatty acid esters in high yields. Enzyme Microb Technol 14:546552 (1992).

9 Kanasawud P, Phutrakul S, Bloomer S, Adlercreutz P and Mattiasson B, Triglyceride interesterification by lipases. 3. Alcoholysis of pure triglycerides. Enzyme Microb Technol 14:959-965 (1992).

10 Garcia T, Martinez M and Aracil J, Enzymatic synthesis of an analogue of jojoba oil: optimization by statistical analysis. Enzyme Microb Techonol 15:607-611 (1993).

11 Fayolle F, Marchal R, Monot F, Blanchet D and Ballerini D, An example of production of natural esters: synthesis of butyl butyrate from wheat flour. Enzyme Microb Technol 13:215-220 (1991).
12 Ramos MC, Gil MH, Garcia FAP, Cabral JMS and Guthrie JT, Immobilization of lipase from Mucor miehei onto poly(ethylene) based graft copolymers. Biocatalysis 6(3):223-234 (1992).

13 Cho SW and Rhee JS, Immobilization of lipase for effective interesterification of facts and oils in organic solvents. Biotechnol Bioeng 41:204-210 (1993).

14 Rocha JMS, Gil MH and Garcia FAP, Synthesis of $n$-octyl oleate with lipase from Mucor miehei immobilized onto polyethylene based graft copolymers. Biocatalysis 9:157-167 (1994).

15 Rizzi M, Stylos P, Riek A and Reuss M, A kinetic study of immobilized lipase catalysing the synthesis of isoamyl acetate by transesterification in $n$-hexane. Enzyme Microb Technol 14:709-714 (1992).

16 Zuyi L and Ward OP, Lipase-catalyzed alcoholysis to concentrate the $n$ polyunsaturated fatty acid of cod liver oil. Enzyme Microb Technol 15:601-606 (1993).

17 Kaimal TNB and Saroja M, Selective removal of linolenic acid from soybean oil by lipase-catalyzed interesterification at low temperature. Biotechnology Lett 10(5):337-340 (1988).

18 Rocha JMS, Marques PAP, Gil $\mathrm{MH}$ and Garcia FAP, Interesterificação de triglicéridos com lipase imobilizada em copolímero de enxerto de base polietileno, Proceedings of III Iberian Congress on Biotecnology, University of Valladolid, Spain. pp 225-228 (1996).

19 Ergan F, Trani $M$ and André G, Solvent free triglyceride synthesis using Lipozyme ${ }^{(i m}$ IM-20 Biotechnology Lett 10(9):629-634 (1988).

20 Lortie R, Trani $M$ and Ergan F, Kinetic study of the lipasecatalyzed synthesis of triolein. Biotechnol Bioeng 41:1021-1026 (1993).

21 Peterson GL, Determination of total protein. Meth Enzymol 91:95-119 (1983).

22 Virto MD, Agud I, Montero S, Blanco A, Solozabal R, Lascaray JM, Llama MJ, Serra JL, Landeta LC and Renobales M, Hydrolysis of animal fats by immobilized Candida rugosa lipase. Enzyme Microb Technol 16:61-65 (1994).

23 Malcata FX, Reyes HR, Garcia HS, Hill CG Jr. and Amundson $\mathrm{CH}$, Kinetics and mechanisms of reactions catalysed by immobilized lipases. Enzyme Microb Technol 14:426-446 (1992).

24 Rocha JMS, PhD Thesis, University of Coimbra (1996).

25 Hansen TT and Eigtved P, A new immobilized lipase for interesterification and ester synthesis, Paper presented at the AOCS World Conference on Emerging Technologies in the Fats and Oils Industry, Cannes (1985). 